The Frontline: Diabetes project can assist family medicine program directors as they incorporate the core competencies of the Accreditation Council for Graduate Medical Education into their residency programs. Besides the acquisition of medical knowledge regarding diabetes mellitus, residents will participate in activities that promote practice-based learning and improvement and system-based learning.

Based upon the preliminary results and the feedback provided by participating family medicine residents, the Frontline: Diabetes project has been a very successful educational program that is significantly impacting a common health care issue.

Peter J. Carek, MD, MS

Professor of Family Medicine, Residency Program Director Medical University of South Carolina

Jobn B. Buse, MD, PbD Professor of Medicine, Chief, Division of Endocrinology University of Nortb Carolina School of Medicine

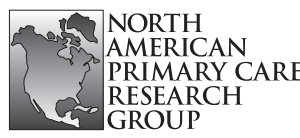

From the North American Primary Care Research Group

Ann Fam Med 2008;6:89-90. DOI: 10.1370/afm. 810.

\section{MAPPING THE FUTURE OF PRIMARY HEALTHCARE RESEARCH IN CANADA}

\section{The Issue}

Family medicine and primary healthcare research in Canada has long been fragmented, under-appreciated, and under-funded. In contrast to the major primary care reform initiatives unfolding across the country, there has been no commensurate effort to build a knowledge base to support the nature and direction of these reforms. How do electronic health records change practice? How can they be harnessed to improve care? What are the effects of working in teams or of blended capitation instead of fee-for-service reimbursement? Does governance of teams matter? How much new after-hours care is there and what is its impact? Are all these reforms helping to attract and retain physicians in primary care careers? The answer to these questions? We don't know and we have no plan to find out.

\section{How Did We Get Here?}

The current level of reform efforts across Canada is unprecedented. Although new models of care are rolling out differently across the country, they all seek to improve access to primary care and they all look to a combination of improved after-hours access, team-based models, new technology, and changes in how physicians are paid. Little is known from other countries about the effects of these innovations, especially whether they result in better patient outcomes. Family medicine has historic strengths in education, especially resident training and continuing professional development, dating at least back to the foundation of the College of Family Physicians of Canada (CFPC) in 1954. Family Medicine research has been a more recent development, at first involving the highly motivated and selftaught, and more recently a cadre of graduate-trained physicians and non-physicians mostly in our academic departments. Nowhere in our country has there been a coordinated plan to build capacity for family medicine or primary healthcare research. Most disappointingly, the formation of the Canadian Institutes for Health Research (CIHR) did not result in an institute for primary healthcare research, nor was there a single special call for primary healthcare grants, teams, research training, or career support during its first 6 years of operation. A large investment in primary healthcare reform, Health Canada's Primary Health Care Transition Fund (PHCTF), ended in 2006, resulting in the formation but later rapid dissolution of research teams. Finally, there is no forum through which researchers in different disciplines and policymakers can even carry on a discussion about what is needed to move primary healthcare research forward.

\section{What Can We Do About It?}

One federal agency, the Canadian Health Services Research Foundation (CHSRF), has included primary healthcare research among its priorities. This same agency recently commissioned a report entitled "Mapping the Future of Primary Healthcare Research" which documented the challenges facing primary healthcare research, especially as the PHCTF funding ended. Led by Dr Grant Russell, it found a lack of support for knowledge generation due to the absence of dedicated funding support for primary healthcare research and career development. It found further problems with the availability of and access to relevant data sources. The report documented major initiatives to build primary healthcare research capacity in other jurisdictions including Australia and the United Kingdom. It made 2 key recommendations: the formation of a national coordinating body for primary healthcare research; and targeted research funding for primary healthcare-specific operating grants, research teams and personnel support. The national coordinating body would help to overcome the fragmentation of primary healthcare research in Canada. It would be broadly representative of researchers, disciplines, funders and policymakers and would develop a research strategy 
and funding plan for building sustainable research capacity. The research funding would help to overcome the historic lack of dedicated research support for primary healthcare and would be used strategically for research training, career development and support, and for helping to answer the key questions involved in primary healthcare reform and renewal.

\section{What Are the Next Steps?}

The recommendations in the report have been strongly endorsed by the CFPC and its Section of Researchers as well as by the North American Primary Care Research Group (NAPCRG), the world's largest primary care research organization. Numerous Canadian professional organizations, provincial funders and policymakers, and national health data and research bodies are in favor of the recommendations. Implementation of the recommendations faces many obstacles, however. The coordinating body needs a host organization and a national body like CHSRF, perhaps in collaboration with CIHR, would be ideal. Once the national coordinating body has been formed, its task of identifying funding will be formidable. Nonetheless, there is reason for hope. Clinicians and decision-makers across the country need answers to pressing questions in the primary healthcare sector. Major investments in unproven innovations are taking place and the public has a right to know if these investments are worth the cost. A groundswell of support to build family medicine and primary healthcare research capacity is forming. CFPC and NAPCRG members can play a role in advocating for these changes and providing whatever support they can locally, provincially, nationally, and internationally. While nothing is so far assured, this is perhaps the best hope in the foreseeable future for moving forward the knowledge base of our discipline in Canada.

Richard Glazier, MD, MPH

University of Toronto

\section{SAFP}

Ann Fam Med 2008;6:90-91. DOI: 10.1370/afm.805.

\section{MEDICAL HOME GAINS PROMINENCE WITH AAFP OVERSIGHT}

The AAFP is continuing its work on building consensus on the importance of the primary care-based medical home. To that end, the Academy in November supported a voluntary designation program that will recognize physician practices as patient-centered medi- cal homes, asked that legislation on Capitol Hill define "medical home" clearly, and successfully urged the Council of State Governments to implement and fund patient-centered medical home pilot projects.

\section{Medical Home Recognition}

The Academy, a charter member of the Patient-Centered Primary Care Collaborative (PCPCC), which represents some of the country's largest corporations, policymakers, consumers and 330,000 primary care physicians, worked with the PCPCC to announce plans for a new voluntary designation program. The program would be administered by the National Committee for Quality Assurance (NCQA), and would recognize physician practices as patient-centered medical homes, a development designed to promote comprehensive and coordinated care.

The NCQA developed the criteria for the recognition program in conjunction with the AAFP, the American Academy of Pediatrics, the American College of Physicians and the American Osteopathic Association. NCQA Executive Vice President Greg Pawlson, MD, $\mathrm{MPH}$, described the criteria as a "roadmap for practices to follow." Program criteria are based on a series of requirements, including patient registries, care management programs, electronic prescribing and followups on tests, among other measures.

Pawlson stressed, however, that the recognition program would not work without adequate payment for physicians. Public and private payers, he said, "have to step forward to recognize the value of the patient-centered medical home and to pay practices appropriately."

AAFP President Jim King, MD, of Selmer, Tenn., explained that physicians themselves cannot be recognized as medical homes; only a physician practice can earn the designation of "patient-centered medical home." That means a patient-centered medical home is a team effort, involving everyone in the practice, said King.

\section{Defining the Medical Home}

The Academy raised concerns about a bill that would provide patient-centered medical homes for some Medicaid recipients and others, saying that key provisions of the legislation should be changed.

Senate bill 2376 would create a medical home demonstration program for certain beneficiaries enrolled in Medicaid and the State Children's Health Insurance Program (SCHIP). Under the legislation, Medicaid and SCHIP beneficiaries without a regular source of care would be assigned to medical homes with primary care physicians who would be responsible for managing and coordinating their care. The legislation also would create local medical manage- 